\title{
DE QUÉ HABLAMOS CUANDO HABLAMOS \\ DE COMPROMISO: DE NUEVO SOBRE \\ LOS POETAS NOVÍSIMOS
}

\author{
WHAT WE TALK ABOUT WHEN WE TALK \\ ABOUT ENGAGEMENT: AGAIN ON THE NOVÍSIMOS POETS
}

\author{
Araceli IRAVEDRA VALEA \\ Universidad de Oviedo \\ airavedra@uniovi.es
}

Resumen: La polémica evaluación del compromiso ha acompañado desde el comienzo a los poetas novísimos, que han quedado relegados del canon asentado de la poesía política. Ello guarda relación con unos planteamientos sobre poética y política, muy arraigados en la historiografía tradicional, que no contemplan el desplazamiento de la conciencia crítica desde el mensaje o el enunciado hacia una problematización del trabajo textual. Justipreciar - ya sin los prejuicios mencionados, pero eludiendo asimismo lecturas voluntaristas - las implicaciones subversivas de algunos rasgos centrales del paradigma novísimo que han tendido a verse como mecanismos evasivos o autorreferentes es el objetivo principal de este trabajo.

Palabras clave: Compromiso. Poesía. Novísimos.

Abstract: The controversial evaluation of engagement has accompanied from the beginning to the novisimos poets, who have been relegated from the established canon of political poetry. This is related to some approaches on poetry and politics, strongly rooted in traditional historiography, which 
do not contemplate the displacement of critical consciousness from the message or the content to a problematization of textual work. The main objective of this article is to measure - without the mentioned prejudices, but likewise avoiding voluntarist readings - the subversive scope of some novisimo's paradigm central features which have tended to be seen as evasive or self-referencial mechanisms.

Key Words: Engagement. Poetry. Novísimos.

\section{LA CRISIS DEL ENGAGEMENT, LOS NUEVE NOVÍSIMOS Y EL RELATO DE CASTELLET}

Mediada la década de los sesenta, la lucidez de Jaime Gil de Biedma ofrecía en su "Carta de España (o todo era Nochevieja en nuestra literatura al comenzar 1965)" tal vez la exposición más penetrante de la concatenación de causas y efectos que por entonces procuraba a la literatura española una conquista crucial para la evolución de nuestras letras: un principio de liberación de cualquier clase de deber extraestético y la puesta en cuestión de la noción de engagement. El poeta dictaminaba en este texto, curiosamente publicado el mismo año en el que Leopoldo de Luis editaba su Poesía social (1965), la caducidad de la tendencia que allí se pretendía potenciar. Y lo hacía después de constatar el desvanecimiento de las viejas ilusiones en un final abrupto del franquismo, así como la desustancialización de la política a que habían abocado las nuevas condiciones de prosperidad y euforia de la sociedad española, tanto como la conciencia emancipada, libre de las hipotecas del pasado, de una nueva generación que no había conocido la guerra. En efecto, esta había dejado de gravitar sobre la conciencia nacional para volverse remota, el nivel de vida del país se elevaba a compás del despegue económico y se abría la puerta a la esperanza. Y la literatura de la posguerra, sensible a las nuevas condiciones de la realidad, también comenzaba a transformarse, pareciendo lo más urgente liberarla de un componente engagé que, a más de haber resultado estéril, se percibía ahora obsoleto y un tanto trivial en su resultado expresivo. De ahí que Gil de Biedma augurase una inminente e "intransigente reacción contra la literatura social que ha predominado [...] durante los últimos quince años", para apuntillar a renglón seguido 
que "en los poetas más jóvenes, ese movimiento ya empieza a dibujarse" (1994: 183-187).

Como es sabido, esa intransigente reacción fue capitalizada por los poetas congregados en la antología Nueve novísimos poetas españoles, publicada por José María Castellet en 1970 aunque comenzara a gestarse dos años atrás. El antólogo cifraba en la oposición a la poesía anterior — que no era otra que la "pesadilla estética" del realismo, y más en concreto, del socialrealismo - su principal marca aglutinadora; y, no en balde, aquellos autores eran presentados como hijos de unos factores extraliterarios que, tal como los enunciaba Castellet, no diferían en esencia de los esgrimidos por Gil de Biedma al dibujar el nuevo clima social y político que ya se respiraba hacia mediados de los sesenta:

Por ejemplo, el vacilante despegue económico; la tentativa de acercamiento a Europa; la tímida, pero efectiva, evolución de las costumbres; la Ley de Prensa de 1966; las polémicas "sindical" y "asociacionista"; la explosión universitaria; la crisis del clero; la ascendente preponderancia cultural pequeño-vanguardista de una Barcelona amilanesada y con capacidad para soportar dos culturas lingüisticas diferenciadas; etc. (2001: 25).

En este contexto cultural emergía, o así quería presentarlo Castellet, el primer grupo generacional que en España se formaba íntegramente desde unos presupuestos que no eran los del "humanismo literario", sino los de los medios de comunicación de masas (2001: 23). Con independencia de la inexactitud del análisis, bien probada a estas alturas, el hecho es que, según el antólogo, esta diferente educación sentimental favorecía la creación de una "nueva sensibilidad" de la que resultaban una serie de actitudes: para lo que aquí nos importa, la proclamación de la autonomía del arte y de la autosuficiencia del poema, en contra del contenidismo de la poesía anterior, "muchas veces didáctico o políticamente energético"; y una tendencia a la frivolidad que se producía también por reacción escéptica a "la humareda de grandilocuencia" de los mayores o, simplemente, por "ligereza intelectual" (Castellet, 2001: 33-36).

En verdad, resulta difícil conciliar la gratuidad estética que se sigue de las actitudes enunciadas, y que parece impulsar una literatura desentendida 
de las vicisitudes históricas, con otro aspecto supuestamente condicionante que asimismo subrayaba Castellet a la hora de situar a sus nueve novísimos: su pertenencia cronológica a la generación que en todo el mundo es protagonista de la "revolución de los jóvenes" (2001: 16). Es probable que, como argumenta con solvencia Lanz, la aparente paradoja pueda resolverse acudiendo a los planteamientos de uno de los pensadores más influyentes en las conciencias sesentayochistas, Herbert Marcuse, cuyas consideraciones sobre la liberación de la vida privada como motor de la liberación social conducían a una "reprivatización de la revolución" y, a su vez, de los espacios de actuación social, con lo que la literatura delimitaba su campo de acción y reivindicaba un espacio autónomo, asimismo reprivatizándose (Lanz, 2011: 146-148). Aunque no parece menos apropiado conjeturar que el aparatoso suceso del mayo francés, un "acontecimiento de escaparate cuya efectividad fue mucho menor que su popularidad" (Prieto de Paula, 1996: 270), tuvo entre nosotros una incidencia sensiblemente más débil que los acontecimientos de la Primavera de Praga, que, si forzaban una modificación del mapa de referencias ideológicas y morales, resultaban particularmente desestabilizadores para los intelectuales españoles, toda vez que la cultura de la resistencia se había nucleado en torno al marxismo y al Partido Comunista. Se trata, en rigor, de concausas no excluyentes que conspiran para propiciar, por un lado, un escepticismo gnoseológico y moral que interviene en la desacralización de la literatura y en la negación de su viejo sentido iniciático; y, por otro, una inflexión en los modos de gestionar el papel subversivo del arte en el imperio de los medios de comunicación de masas.

En todo caso, Castellet ya advertía en el prólogo a su antología tanto de la doble interpretación que los nuevos poetas ofrecerían de su educación sentimental —esa formación ajena al viejo humanismo - como de una serie de tensiones internas que, afectando a elementos como la diversa asunción del camp, o el distinto planteamiento del cogito interruptus, podían apuntar a divergencias de fondo no sin relación con la intención político-social susceptible de leerse en algunos. No cabe olvidar, por último, que la reivindicación de la autosuficiencia de la forma ya no podía interpretarse a aquellas alturas de los años sesenta, o no necesariamente, como un modo de descompromiso ideológico; pues lo que prevalecía era un clima teórico que, con autores como Adorno o McLuhan a la cabeza, venía a postular la ideologización de la forma o la contenidización del 
medio, al sostener que la clave del contenido del arte reside en su técnica. Resultaba así cuestionada la supuesta neutralidad de una palabra artística que, más que mera transmisora de un contenido o de una ideología, era la ideología misma (Lanz, 2011: 143), según por cierto sugería Castellet al interpretar el célebre aforismo de McLuhan: "la forma del mensaje es su verdadero contenido" (2001: 36). Y, de hecho, esa forma contenidizada admitía ser leída, al menos en algunos de los antologizados, como un modo distinto de cuestionamiento social: así sucedería, por ejemplo, con aquellos que acudían al irracionalismo con una "voluntariedad de ruptura con una lógica sociolingüística que traduce los esquemas organizativos de una sociedad irracional y represiva" (Castellet, 2001: 34).

Aun así, el matizado discurso de Castellet se mostraba ciertamente vacilante a la hora de pronunciarse sobre la potencia o sobre la voluntad subversiva de la obra de sus nueve novísimos, en parte debido al forzado intento de aglutinación de poéticas dispares y no siempre asimilables. Conviene, por ello, ceder la palabra a los interesados, así como a otros colaboradores en la renovación estética - los llamados por Ignacio Prat "para-novísimos" (1983: 215)— que, inmediatamente incorporados a otras antologías asimismo fundacionales (Nueva poesía española, de Enrique Martín Pardo y Espejo del amor y de la muerte, de Antonio Prieto), tuvieron algo que decir acerca de la impronta ética de su escritura.

\section{NUEVE NOVIISIMOS Y ALGUNOS MÁS: AUTOLECTURAS Y SUS RÉPLICAS}

Si una cosa confirman la mayoría de poéticas recogidas en Nueve novísimos respecto de la caracterización de Castellet, es la anunciada consideración del poema como reducto autosuficiente, como única realidad al margen de todo elemento situacional; y ello no solo a resultas de la consabida vocación antirrealista, sino como corolario del también mencionado escepticismo epistemológico — relativo a la capacidad del hecho poético para la penetración de lo real—, casi siempre indesligable de un escepticismo de índole moral - relativo a la posibilidad de modificación de esa realidad-. Algunos años después, en el prólogo a la poesía reunida de Guillermo Carnero, Carlos Bousoño cifrará precisamente la más determinante característica de la generación en su conciencia de la incapacidad de la razón racionalista para conocer la realidad individual, de 
ahí que las palabras "remit[a]n a un mundo que no es el de la experiencia, sino que el propio hecho poemático se ha encargado de construir", esto es, "el arte, lo artístico como tales" (1983: 26, 32). Pero tal conciencia, a la postre, no solo explica la remisión del arte al mundo del arte, sino que ofrece las claves de una de las más genuinas (y denunciadas) actitudes del autor-modelo novísimo y nos lleva a la médula de nuestra reflexión: la frivolidad, la reivindicación de la idea orteguiana de la intrascendencia artística y de la concepción lúdica del fenómeno literario: "Entendíamos la poesía - evoca uno de ellos - tal y como la entendían los antiguos alejandrinos: momentánea y circunstancial, festiva, intrascendente, divertida e inútil" (Cuenca, 1979-1980: 250).

No hay que descartar en esta ligereza, tal y como postulaba Castellet, una reacción a la "humareda de grandilocuencia" de los mayores; pero lo que actúa sobre todo es la constatación de la inutilidad del arte y la descreencia radical del valor de la poesía, a la que se exonera en consecuencia de cualquier meta trascendente. No obstante, no es en este punto - como no lo es en ninguno- homogénea ni estable la posición de los novísimos, ni siquiera de los primeros y genuinos de la selección de Castellet; aunque sin duda predominen en estos las actitudes desacralizadoras que, por descontado, excluyen aquella poesía "didáctica o políticamente energética" extemporánea en la nueva coyuntura. Atiéndase a algunas significativas declaraciones: Vázquez Montalbán considera que "la poesía, tal como está organizada la cultura, no sirve para nada" (en Castellet, 2001: 57); para Martínez Sarrión, "la poesía no podía ser en nuestra circunstancia un instrumento de agitación política" (88); a José María Álvarez "escribir, aparte de todo, [le] parece una especie de juego" (109); Félix de Azúa expresa su "escepticismo sobre las posibilidades que tiene la poesía de cambiar el mundo" (135) y, en consecuencia, entiende que "el poeta trabaja el poema bajo coordenadas literarias independientes de otras provocaciones" (en Campbell, 1994: 75); y un Guillermo Carnero manifiestamente descreído - "no hay nadie que ponga a la literatura tan en bajo nivel como la pongo yo"- declara que esta solo sirve "para jugar" (en Campbell, 1994: 50-51).

$\mathrm{Y}$, sin embargo, habrá que recordar que aquella displicencia un tanto sobreactuada tuvo en algunos caducidad muy inmediata. En la poética incluida en Nueva poesía española, editada por Enrique Martín Pardo en el mismo año que Nueve novísimos, pero atenuadora de las marcas de ruptura, 
Pedro Gimferrer ya conjugaba la preocupación por el rigor estético con un designio de insubordinación - "la contravención expresa o tácita del sistema represivo de la sociedad" - que de pronto reclamaba a la escritura; así como "un planteamiento moral en términos claros" que vinculase a la poesía con los asuntos de la vida diaria (en Martín Pardo, 1990: 27). $\mathrm{Y}$ en una entrevista concedida por las mismas fechas, no vacilaba en atribuirle expresamente una "misión" extraestética: "evidenciar y resolver las contradicciones de la realidad: hacer que el poema sea un vehículo liberador, contravenir lo establecido, replantear los problemas esenciales, denunciar la falacia del lenguaje codificado" (en Campbell, 1994: 71).

Claro que ha de ser en la esfera del lenguaje, no en la del mensaje como plano separado de ideas, donde se juegue cualquier operación denunciadora: de ahí que Gimferrer solicite una poesía que haga "un problema de la relación entre las palabras y la realidad práctica", en la idea de que toda formalización lingüística lleva implícito "un planteamiento de la realidad" (en Martín Pardo, 1990: 27-28). No lejos de esta convicción, Jaime Siles, presentado a la sociedad literaria en la misma antología de Martín Pardo, ha reivindicado con los años en la poética novísima una meditada estrategia de beligerancia contra el sistema político y social:

Los novísimos vieron en la cultura una forma de oposición al poder y buscaron la recusatio de este [...] en una poética explícita e implícita, que no era otra que la alejandrina. El alejandrinismo de los novísimos era tan estético como moral, y se basaba en la fe en la cultura y en la fe en el lenguaje, entendidos ambos [...] como un sistema de oposición: de oposición a la incultura, a la barbarie y a los modos de aculturación que el franquismo ofrecía [...]. Frente a estos modos, los novísimos buscaron la libertad en el texto e hicieron de aquella y de este - de aquella en este- un punto generador de una nueva y distinta realidad más amplia (1989: 10).

Para Siles, la retórica novísima codificaba una revolución que, al subvertir el instrumento lingüístico, y vulnerar de este modo el conjunto de normas impuestas por él, socavaba los cimientos mismos del franquismo con bastante más eficacia de la que había logrado la poesía social. Hay que 
decir, ahora bien, que tampoco en esta segunda oleada de poetas novísimos hallamos consenso en la interpretación de un presunto compromiso como actitud inscrita en el trabajo textual. Luis Alberto de Cuenca, que se reconocía asimismo en el espejo del alejandrinismo, veía intrascendencia y ligereza donde Siles encontraba oposición y lucha; la gratuidad era para él la marca del ejercicio creativo de la "generación del lenguaje":

Nuestra tarea no ha sido más que un juego, una empresa para amateurs sin metas ni objetivos. [...] Nos distraíamos $y$ huíamos de las cosas en silencio y melancolía [...] De lo que principalmente se trataba era de eludir toda responsabilidad estética, artística y literaria, de distraernos del tiempo por medio del subterfugio que más nos agradaba (1979-1980: 246, 251).

Y así fue, de hecho, como se interpretó las más de las veces el ejercicio poético novísimo, que desde muy tempranas fechas desató una severa contestación a lo que se percibía como una literatura irresponsable y frívola, connivente con un sistema político que aún demandaba oposición intelectual y del que, en cambio, los jóvenes poetas parecían desentenderse. Son a este respecto muy elocuentes los madrugadores juicios que pueden leerse en el "Apéndice documental" que acompaña a la reedición en 2001 de Nueve novísimos poetas españoles, y que recoge fragmentos de textos y reseñas que contribuyeron a hacer de la antología un verdadero acontecimiento editorial en el momento de su aparición. Así, Julián Chamorro Gay publicará en la revista Álamo una reseña en la que acusa a los seleccionados de incurrir en conservadurismo, no siendo "conscientes del idealismo que la renovación formal por sí misma, o la construcción de literatura sobre literatura, trae consigo" (en Castellet, 2001: 17). Juzgando la poesía que allí se mostraba como un subproducto de la realidad estructural del país, Juan Antonio Masoliver Ródenas, en su noticia para La Vanguardia Española, encuentra en la antología "un fiel reflejo de nuestras actitudes: el rechazo de los valores morales, sociales y políticos que nos lleva a la negación de todo valor" (24). Por su parte, Gaspar Gómez de la Serna, en un texto publicado en Arriba, convierte a los poetas de la ruptura en "agentes de la cocacolonización, $[\ldots]$ al servicio de los intereses económicos de un nuevo imperialismo" (30). Y, en fin, uno de 
los jóvenes poetas más beligerantes con la selección, José-Miguel Ullán, ve renacer en esta "una poesía providencial, esteticista y neodecadente a tono con los balbuceos precapitalistas de un país mentalmente medieval" (22).

En convergencia con estos planteamientos, no tarda en surgir una contundente réplica antológica a la operación castelletiana. Se trata de Teoría y poemas, a cargo del Equipo Claraboya, que nace en 1971 asumiendo entre sus objetivos primordiales el de desenmascarar el supuesto carácter revolucionario - sugerido, sin ir más lejos, en las declaraciones citadas de Gimferrer - de la poética presentada en Nueve novísimos y que allí llaman "neodecadentismo". Aunque aplaudan los logros lingüísticos de este, los claraboyistas denuncian la incorporación al poema de efusiones anímicas estrictamente personales, la exclusión sistemática de los aspectos "indignos" de la realidad — a cambio de la agregación de ingredientes destinados a los consumidores del capitalismo rampante-, así como la frivolidad y el esteticismo. Y atajan cualquier proclividad a interpretar el retiro novísimo en la gratuidad estética como un modo de impugnación del sistema vigente, alzándose contra una poesía "integrada" en la que no hay expresión de la realidad pero sí adecuación con ella: una poesía que, en suma, y coincidiendo con las críticas arriba consignadas, consideran "reflejo del incipiente neocapitalismo en un sector muy minoritario de la burguesía catalana joven" (Delgado et al., 1971: 16-18).

En fin, pasados los años, cuando la estética novísima había sido abandonada por sus principales cultivadores, uno de los poetas más combativos con los nuevos bardos se despachaba con un severo y muy contestado análisis de la "Poesía española contemporánea". Bajo este título, Ángel González denunciaba la rara neutralidad de una literatura desprovista de cualquier impulso ético, social o político como acicate del poema y aplicada, a cambio, "a escribir odas sobre mares más o menos venecianos o sobre mitos más o menos de celuloide" mientras la represión y la censura seguían existiendo. La ignorancia de tales circunstancias y la temprana suposición por los novísimos de la inexistencia del dictador, sostenida en la franca decadencia de este y en algunos espejismos, como la Ley de Prensa o la euforia aparejada al desarrollo económico, no convertían sus productos en cultura subversiva, sino más bien hacían de ellos una secreción final del franquismo: 
El irracionalismo, la gratuidad de muchas de sus teorías, el deslumbramiento ante lo "moderno", la desrealización, la mitificación del lujo, la consideración del arte como experimento perpetuo, la insistencia en los aspectos técnicos de la escritura, cierto innegable triunfalismo, las fijaciones elitistas y aristocratizantes, son [...] rasgos que deben ser interpretados no como una "contestación", sino como un fiel eco de la España de López Rodó, de los tecnócratas del Opus, del monseñor que quiso ser marqués, del optimismo oficial basado en falsas estadísticas (1980: 7).

La cultura de la subversión, como en parte se ha adelantado, se canalizaba por otras vías (elípticas, y casi siempre asociadas a la problematización de los significantes) que tampoco González estaba dispuesto a reconocer como válidas. Aun así, existieron propuestas que escapaban visiblemente a esta caracterización, como ha de verse próximamente y como, de hecho, ya había apreciado Félix Grande con notable perspicacia y mucha antelación. Pues, en efecto, entre tantas opiniones tendiendo a desabridas, el poeta hacía oír su voz discordante $\mathrm{y}$, en el mismo año de publicación de Nueve novísimos, trataba de zanjar la polémica como sigue: "Decretar, [...] apoyándose en una desrealidad programática de los 'novísimos', creo que muy vertiginosamente desenmascarada, que la actual poesía española se ha vuelto deshuesada y reaccionaria me parece [...] una majadería". Claro que, digámoslo todo, Grande formulaba aquí un juicio global sobre la poesía española joven que, como advertía, no acababa en la antología castelletiana, lo que le permitía concluir con toda rotundidad que esa poesía " $\mathrm{n}[\mathrm{o}]$ ha degollado a sus viejos y emocionantes compromisos" (1970: 104-105).

\section{DE QUÉ HABLAMOS CUANDO HABLAMOS DE COM- PROMISO: TEORÍAS Y PRÁCTICAS DE LA SUBVERSIÓN}

Con todo, y a la vista de sus propias consideraciones al respecto, parece difícil admitir sin algún voluntarismo la existencia de un generalizado y resuelto designio de oposición política en la actitud creativa de los novísimos; oposición que se jugaba, de hacerlo, por modo 
sobreentendido o negativo, mediante un cuestionamiento de las formas o el refugio en el lenguaje. Y he aquí que acabamos de mencionar los dos factores determinantes de la clase de percepciones a que mayoritariamente ha dado lugar el asunto del compromiso en la práctica poética de estos autores, que han tendido a quedar relegados del canon parcial de la poesía política, al menos en sus formulaciones más asentadas. En un artículo precisamente titulado "El canon del compromiso", Antonio Méndez Rubio cuestionaba hace unos años los planteamientos sobre poética y política operantes en los principales estudios sobre el compromiso poético español del pasado siglo, planteamientos de trascendencia no menor por cuanto han tenido repercusiones decisivas en la propuesta canónica resultante. Sobre todo, este autor atendía al enfoque de Lechner en su clásico libro sobre El compromiso en la poesía española del siglo XX (1968), para llamar la atención sobre los dos supuestos centrales que el hispanista ponía en juego como precondiciones del compromiso - junto con "la intención consciente del escritor que elige esa posición de enunciación”, "el principio de realidad como eje" del poema que debe reflejar la experiencia social- $\mathrm{y}$ alertar sobre el "régimen de exclusiones" que tales precondiciones habían generado. El modelo de compromiso defendido afectaba, en efecto, cuando menos al descrédito en bloque del arte de vanguardia o no figurativo, y proyectaba toda una zona de sombra sobre amplias parcelas de la poesía contemporánea que, desde un enfoque menos tradicionalista, habrían arrojado una luz distinta sobre la categoría considerada. Ello conducía a Méndez Rubio a concluir que "las limitaciones del canon del compromiso se derivan de un previo compromiso con el canon (realista 'en el sentido usual de la palabra')" (2007: 217-224).

La reproducción inercial de estas premisas intervino sin duda en la polémica evaluación del compromiso que desde el comienzo acompañó a la poesía de los novísimos. Ya que, por un lado, solo algunos mostraron intención consciente o autoconciencia responsable (hecho en verdad irrelevante si aceptamos que los nexos con la Historia no dependen de las decisiones individuales, porque siempre se escribe desde un "lleno" ideológico [Rodríguez, 2002: 54]); y, por otro lado, prevalece con mucho en ellos, sobre el "lenguaje de la realidad", lo que el propio Méndez Rubio ha llamado la "realidad del lenguaje", o un modo de replantear el compromiso que parte de "una crítica del (absolutismo del) reflejo" y defiende que la realidad es "un mundo percibido y construido" por la escritura (2002: 44). 
Así las cosas, la imputación de escapismo y gratuidad ha recaído más que a menudo sobre esta modalidad de compromiso que fundamentalmente se resuelve en una tarea de crítica y construcción de lenguajes.

Conviene establecer, ahora bien, distinciones y matices, puesto que el modelo estético novísimo no es en modo alguno uniforme ni compacto, y ni siquiera los ingredientes o estrategias más inequívocos de este paradigma están sujetos a usos equiparables entre los autores que los asumen. Evaluar, ya sin los prejuicios denunciados, pero eludiendo asimismo lecturas voluntaristas, sus distintos significados e implicaciones respecto de la categoría del compromiso será el único modo de dirimir el alcance efectivo de la subversión en la poesía novísima.

\subsection{El culturalismo}

Pese a la determinación subversiva de las declaraciones de Gimferrer en su poética para Nueva poesía española, en la veta intensamente esteticista, decadentista y neobarroca que representa este autor y emblematiza Arde el mar (1966), seguramente acompañado en su forma más brillante y acabada por Guillermo Carnero y su Dibujo de la muerte (1967), no es fácil reconocer, ni por empeño ni por logro, un trabajo inmediato de erosión política. Puede traducir, sin embargo, muy factiblemente un desapego de las circunstancias ambientales. Ya se sabe que este vector fundamental del cambio estético ponía el acento en la recreación de la belleza y, a la zaga de parnasianos y simbolistas, sustituía las referencias a la realidad inmediata por un mundo imaginario en gran parte contrahecho con elementos provenientes de la tradición cultural barroca (García de la Concha, 1986: 18). En este contexto cobra sentido la interpretación de Jaime Siles, para quien la articulación de un universo referencial que evita convocar directamente la experiencia traduce "el modo de luchar contra un medio en el que, hasta la vida, era algo que había que inventar". Siles entiende, así, el culturalismo novísimo como un culturalismo vitalista que, mediante la invención de la belleza, busca la reinvención de un entorno inmediato que despierta desdén en el poeta (1989: 10-11). La hipótesis vale para explicar la acostumbrada remisión nostálgica a épocas del pasado, o a lugares caracterizados por su estilización o su exotismo y prestigiados por la historia cultural, como fuga de lo "falso", lo "feo y aburrido" que asedia al sujeto (Gimferrer, 1996: 25). Y en verdad no faltan versos que la avalen, 
y que hallamos, sin ir más lejos, en el emblemático "Cascabeles" (Arde el mar) de Pedro Gimferrer, quien explícitamente contrapone y reivindica los tiempos festivos de la belle époque frente a las luctuosas sombras del presente:

Maceración de lirios, el antiguo gran mundo

paseaba sus últimas carrozas

por los estanques que invadían el légamo.

$Y$ en el aire flotaba ya un olor a velones, a cilicios,

a penitenciales ceras, a mea culpa,

a reivindicaciones

de inalienable condición humana.

[...]

Yo, de vivir, Hoyos y Vinent, vivo,

tanto daríamos, creedme,

para que nada se alterase, para

que el antiguo gran mundo prosiguiese su baile de galante harmonía,

[...]

no pereciese nunca (en Castellet, 2001: 158-159).

En otro sentido, y apoyando ahora la interpretación, que también más arriba ofrecía Siles, del empeño o la fe en la cultura como un sistema de oposición al raquitismo cultural a que el régimen había condenado a los españoles, se encuentra la consideración de la práctica culturalista, ofrecida por Guillermo Carnero, como el corolario externo y visible de una apuesta por "la posesión pública y pacífica de la cultura": algo en lo que podría verse, según quiere Méndez Rubio (2004: 23), una voluntad de afrontar críticamente una democratización de la cultura como forma de transformar la realidad social. Tal afán democratizador resulta, desde luego, inocultable en el Vázquez Montalbán que promueve la síntesis de cultura de masas y cultura de élite bajo un collage integrador de evidente alcance ideológico. Sin embargo, en Carnero, las implicaciones políticas de ese "ecumenismo cultural liberador" resultan de algún modo cuestionadas por el mismo discurso que lo propone, al reclamar a su vez como otra motivación no menos poderosa del culturalismo generacional "la adopción de un concepto de literatura que no le reconoce ninguna finalidad extraliteraria" (Carnero, 
1990: 13). O dicho de otro modo: "nuestra poesía fue una proclamación de libertad en su ausencia de condicionamientos políticos" (en Méndez Rubio, 2004: 125-126). Ello pone asimismo en entredicho la propuesta de lectura de Trevor Dadson, quien ha visto en la reapropiación carneriana de símbolos y mitos culturales de la España áurea, en que fundó el franquismo su legitimación histórica, un "ataque deliberado" a este y una "verdadera poesía de engagement" (2000: 126, 136).

$\mathrm{Y}$ es que, en el fondo, y como concedió Gimferrer mucho más tarde, era aquella una literatura que, aun "queriéndose los más diferente posible de la impostura que la rodeaba", "no iba directamente contra el entorno social, sino que era una protesta indirecta que no era política, sino estética" (1996: 25). Así que el culturalismo novísimo se alzaba, al fin, contra el lenguaje de la poesía académica, contra el lenguaje del poder literario mucho antes —o solo a través de esa perífrasis - que contra el lenguaje del Poder, de tal modo que la evidente subversión cultural no se manifestó como política estricta; antes al contrario, todo aquello suponía un asentimiento a la imagen de la sustantividad poética promovida por el sistema a cambio de la desustancialización de la política (Rodríguez, 1999: 268-270). En este punto, como bien ha visto Lanz haciéndose eco del análisis de González arriba citado, estos autores

olvidaron el enfrentamiento ideológico que los paralizaba en el tiempo para avanzar, ignorando el propio sistema franquista, por un camino que les facilitara la integración cultural en Europa [...]. Paradójicamente, esta postura los hizo, en cierto modo, partícipes de la desideologización que pretendía el régimen (1997: 16).

\subsection{El camp}

La incorporación de elementos de gusto camp, otra inconfundible aunque mucho más efímera característica de la generación, obedece entre sus cultivadores a motivaciones no asimilables, como en alguna ambigua medida ya había adelantado Castellet. En la citada reseña de Nueve novísimos publicada en La Vanguardia Española, Masoliver Ródenas también discernía entre la "prematura nostalgia de la infancia" y la importada "cultura de "posters"" que denotaba el culto a la civilización de 
los mass media por parte de cierta coqueluche — "el mediocre poema de la Moix muestra la máxima altura de la cultura 'poster', solo superado por el de Leopoldo María Panero"- y la mucho más adecuada incorporación de esta cultura en la obra de Vázquez Montalbán (en Castellet, 2001: 24). Juicios de valor al margen, el hecho es que erraríamos sin duda si leyésemos de análogo modo las implicaciones de este rasgo en el Vázquez Montalbán de Una educación sentimental (1967), el Martínez Sarrión de Teatro de operaciones (1967), el Pedro Gimferrer de La muerte en Beverly Hills (1968) y el Leopoldo María Panero de Así se fundó Carnaby Street (1970).

En su prólogo a la antología, Castellet seguía a Susan Sontag para explicar la sensibilidad camp cuando menos en la poesía de la coqueluche, donde aquella se manifestaba como un índice del gusto - heredero del Modernismo - por lo artificioso y por lo exótico. Sontag definía el fenómeno camp como una manera de mirar el mundo en su dimensión estética y "como un modo de deleitarse, de apreciar, pero no de enjuiciar" (en Castellet, 2001: 31). Si ello era así, tal asentimiento lúdico a los valores estéticos implicaba, en un comportamiento similar al de los creadores del Modernismo o del decadentismo fin de siglo, una actitud de "suspensión de toda creencia" (Carnero, 1983: 50), y representaba la voluntad de abandonar el compromiso con la realidad histórica para sentir "sub specie estheticae" (García de la Concha, 1972: 55). No obstante, y de un modo similar a como algunos quisieron ver tras el culturalismo y su refugio en un pasado de belleza la implícita condena del elidido mundo cotidiano, no han faltado interpretaciones de la indiferencia de lo camp, en tanto negación absoluta de un estado de cosas, como una veta crítica de la "civilización de la opulencia” (Martínez Ruiz, 1971: 14).

Más allá, Juan José Lanz ha apreciado también cuestionamiento y denuncia en algunos poemas de la coqueluche que proponen una perspectiva heterodoxa de la mítica popular, tal es el caso del uso de la iconografía infantil -Peter Pan, Blancanieves - por Leopoldo María Panero. Con independencia de la perspicacia del análisis, ya que es innegable la dimensión "perversa" que adquiere el tratamiento de tales mitos en el primer poemario paneriano, requiere tal vez algún voluntarismo leer en esa recontextualización de la mitología infantil una deliberada crítica al sistema educativo $y$, por extensión, a todo el sistema social padecido por la generación del tardofranquismo a que pertenece el autor (Lanz, 2011: 
154). A cambio, podría pensarse quizás en un pudoroso deseo de sofocar la incontenible nostalgia de la infancia — "Os echaré de menos, nunca os olvidaré", declara el sujeto de uno de los poemas- que, al cabo, parece estar en la base de un libro como Así se fundó Carnaby Street, con el que se trataba de aludir "a una situación anímica de fin de mundo" (Panero, 2001: 77), fundada en la arraigada convicción paneriana de que "en la infancia vivimos y [...] después sobrevivimos" (en Chávarri, 1976: 78). Aunque habrá que convenir, con Prieto de Paula (1996: 318), en que la opacidad intencional en el tratamiento de esta mítica impide una valoración unívoca.

Sin embargo, menor riesgo comporta afirmar la presencia de un verdadero corolario crítico en el empleo de lo camp por autores como Vázquez Montalbán o Martínez Sarrión. Si este recurso funciona mayoritariamente en los novísimos, igual que el disfraz culturalista, como un campo simbólico de referencias estéticas que esquiva la noticia directa del yo y la realidad (valga el caso paradigmático de Gimferrer y La muerte en Beverly Hills), los iconos de la cultura de masas constituyen en los poetas citados, en tanto evocaciones biográficas que son, un lenguaje sentimental propio y asumido. Y antes que como categorías de artificio y vías de evasión, actúan como irónico instrumento de penetración crítica, sin que falte por ello la tenue adhesión afectiva. Así, bajo la entonación desenfadada y frívola con que son convocados los emblemas populares late una ambigua impugnación de la sociedad en que surgieron, que no suele ser otra que la España castiza y folklórica diseñada por la voluntad autárquica del sistema franquista (Carnero, 1983: 54; Prieto de Paula, 1996: 318). El ejemplo emblemático puede ser aquí "Conchita Piquer" (Una educación sentimental), que abre la muestra poética de Vázquez Montalbán en la antología castelletiana. La cupletista que da título al poema, y la célebre letra de "Tatuaje" que se inserta fragmentariamente en el texto, no solo coadyuvan al dibujo de la sórdida realidad española de la alta posguerra, en la que la copla, vivamente potenciada por el régimen, se halla fuertemente arraigada; además, esta clase de ingredientes mítico-festivos de una cultura alienadora divulgada desde las emisiones triunfalistas de Radio Nacional de España comparecen como ilusorios refugios frente al mundo de humillaciones y miseria en que se encuentra sumido un país social y económicamente devastado:

\section{Algo ofendidas, humilladas}


sobre todo, dejaban en el marco

de sus ventanas las nuevas canciones

de Conchita Piquer: él llegó en un barco

de nombre extranjero, le encontré en el puerto

al anochecer

y al anochecer volvian

ellos, algo ofendidos, humillados

sobre todo, nada propensos a caricias

por otra parte ni insinuadas

[...]

Acababa Glenn Miller y Bonet de San Pedro

les cantaba los paisajes mallorquines, la voz

insinuante de la locutora de un hotel:

langostas vivas, consomés insuperables, el mar

un alimento de yodo desde la miranda

acondicionada

de un hotel a la altura de los entonces derruidos en Europa (en Castellet, 2001: 59-60).

El recurso a la mitología popular como arma arrojadiza contra un estado de cosas, en la medida en que establece el contrapunto luminoso de la sombría realidad circundante, opera con todo más palmariamente en "el cine de los sábados" (Teatro de operaciones), composición de Martínez Sarrión que inaugura asimismo el conjunto de textos del albaceteño en Nueve novísimos. Allí, el universo mítico del cine de Hollywood se establece como paréntesis de la mezquindad ambiental y vale para dar cuenta de una "infancia dividida" entre la felicidad y la grisura, entre el "mundo [...] acongojante y rutinario de la realidad" (Martínez Sarrión, en Campbell, 1994: 153) y la ensoñación candorosa que halla refugio en los primeros estímulos eróticos o en las ficciones sublimadoras de la cultura:

yvonne de carlo baila en scherezade

no sé si danza musulmana o tango

amor de mis quince años marilyn

ríos de la memoria tan amargos

luego la cena desabrida y fría

y los ojos ardiendo como faros (en Castellet, 2001: 91). 
Pero este designio crítico alcanza también a otros sistemas sociales generadores de mitos. Paradigmática en este sentido resulta la "Requisitoria general por la muerte de una rubia", del Martínez Sarrión de Pautas para conjurados (1970), donde el homenaje al icono popular de Marilyn Monroe, fallecida a causa de una sobredosis de barbitúricos, se propone como sátira de la sociedad capitalista norteamericana, que ha convertido a la estrella de Hollywood en "la víctima de un sistema cuyo valor supremo es el éxito a través de la competencia encarnizada" (Martínez Sarrión, en Campbell, 1994: 154-155). Martínez Sarrión agrega así a la evocación de la actriz como icono sexual que funcionaba en "el cine de los sábados", y que encarnaba una forma de transgresión de los modelos impuestos por la pacatería del franquismo, un componente acusatorio ya insinuado en el término jurídico del título:

mil barcos de basora cargados con especias

techos de muérdago happy

christmas vigilias

esperando los besos imposibles

también

ellos los hornos crematorios

los pájaros nocturnos rebosantes de herrumbre

la sofocada baja amenazante noche

boulevard

del crepúsculo

ráfagas

de terror en los ojos enormes de mi amor

aferrada a su sucio frasco de nembutal (en Castellet, 2001: 101).

\subsection{La metapoesía}

También es susceptible de ser discutida la dimensión crítica del discurso metapoético, otro de los rasgos principales de la estética novísima a partir de 1970-1971. Si hay consenso en que al fondo de este ejercicio autorreferente se agazapa la severa sospecha de la inutilidad del arte, la reticencia respecto a su capacidad para comunicar verbalmente 
una experiencia y conocer el mundo, corresponde a Carlos Bousoño la más vehemente defensa de las implicaciones subversivas que asimismo podría contener el empleo de la función metapoética y la reflexión sobre el lenguaje. Según el planteamiento que formula en el prólogo a la poesía reunida de Guillermo Carnero, el discurso de una poesía que habla de la poesía perseguiría el desenmascaramiento del lenguaje en cuanto código dominado y manipulado por el poder, e implicaría una manifiesta rebeldía contra ese poder represivo y deshumanizador. La concepción de la poesía como metalenguaje buscaría, en suma, contestar "los mecanismos uniformadores, deshumanizadores y represores del Poder" discutiendo su propio código, ya que "no se puede atentar contra el Poder represor mediante un código que aquel ha puesto en uso precisamente para disponer de un mecanismo de conservación basado en el funcionamiento automático" (1983: 27-29). Aunque tal razonamiento fue inmediatamente suscrito por Guillermo Carnero - que entendió el cuestionamiento del discurso literario como una enmienda a la totalidad del discurso cultural (1983: 71)—, e incluso anticipado por el Pedro Gimferrer que demandaba "un planteamiento poético de la realidad" - aquella problematización de su relación con la palabra-, cabe sin embargo preguntarse, con Prieto de Paula, si la desautomatización que desvela tales mecanismos represores atenta ideológicamente contra ellos: "esto es, si además de desveladora es debeladora, o si [...] se limita a evidenciar que se está al cabo de los mismos con una sabiduría de la realidad pareja al escepticismo sobre la capacidad de modificarla" (1996: 230). Se diría, en efecto, que la constancia de las secuelas represivas de los códigos al uso raramente canaliza un impulso combativo en el interior de la escritura, ya que se da la absoluta descreencia en su eficacia instrumental, en su capacidad para actuar efectivamente en la modificación de las estructuras opresoras. Es lo que sugiere, aún sin salir de la antología castelletiana, "El movimiento continuo" (Dibujo de la muerte) de Guillermo Carnero, una crítica a la ética del orden de las gentes "comme il faut" que, presidido por una cita de Rober Herrick anticipadora del corolario pesimista — “....pronto envejeceremos; moriremos antes de conocer la libertad"-, concluye con una desoladora reflexión sobre la imposibilidad de sustraerse a los mecanismos de conservación puestos en juego por un poder que invalida cualquier movimiento progresivo en la inoperancia reiterativa de la circularidad: 
Alguien descubrió que el tiovivo podía seguir girando [...] Vosotros, mientras en la noche resuena la rutilante música de circo, decidme si merecía la pena haber vivido para esto, para seguir girando en el suave chirrido de las tablas alquitranadas,

para seguir girando hasta la muerte (en Castellet, 2001: 202).

Claro que tampoco existe homogeneidad en la consideración de este recurso. Y, a este respecto, es preciso referirse a los planteamientos defendidos por Jenaro Talens, uno de los autores más reincidentes en la práctica metapoética, aun rechazando el término de metapoesía como tal — "la metapoesía no existe, o bien no existe la poesía" (1981: 18)—. Pese a insistir en que la problematización de los elementos formales no tiene por qué entenderse como divertimento evasivo sino, antes bien, como un intento de desvelar los mecanismos de significación, este autor reclama un paso más en el ejercicio autocontemplativo de la poesía de su generación:

La alternativa no tiene lugar entre tradicionalistas [...] y cuestionadores técnicos o metafísicos del lenguaje [...]. Ambas no son sino las dos caras de una misma moneda. El objeto de la poesía no es su autocontemplación sino colaborar a la transformación de la realidad, de ahí que su materia no sea, como quería Stevens, la propia poesía, sino el análisis de la manipulación de los hombres en la Historia a través del lenguaje. Constatar los medios sintácticos, morfológicos, técnicos que lo hacen posible es únicamente una primera etapa, nada más. Entre esta última postura y la doble citada con anterioridad es donde la verdadera alternativa se establece (en Batlló, 1974: 280-281).

Si esto escribía Talens en una poética de los años setenta, en su estudio prologal a la poesía de Antonio Martínez Sarrión establece en el uso de la que prefiere llamar "función metapoética" tres categorías diferenciadas: aquella que se manifiesta como lenguaje analítico, la que lo hace como lenguaje reflexivo y la que actúa como lenguaje crítico. Si todas implican 
una reflexión sobre el poder, por cuanto este se halla forzosamente inscrito en el lenguaje, solo a la tercera le concede una verdadera efectividad, y ello en la medida en que no se sirve del lenguaje como medio (con lo cual desaparecen los juicios de valor y las implicaciones de saber: es decir, de poder), sino como puro gasto gratuito, como puro placer sin finalidad $-\mathrm{y}$ "nada más subversivo en un orden levantado sobre el valor del dinero y la productividad que la gratuidad del goce"-. El desenmascaramiento de los mecanismos represores del poder se vería entonces paradójicamente realizado sin hablar de él (Talens, 1981: 18-19).

En suma, según el planteamiento talensiano, solo la desinstrumentalización del signo lingüístico, la emancipación de su función referencial y la liberación, en fin, del sentido posibilita una verdadera subversión. Desde aquí se explicaría la textualidad de una parte importante de su producción, muy conscientemente encaminada a boicotear la unicidad semántica y toda posibilidad de reducción a un sistema cerrado, en congruencia con su desconfianza de un sistema representativo supuestamente natural y neutro en el que se inscribe de hecho la ideología del poder. Se trataría, para decirlo con un verso de Martínez Sarrión, de "nombrar como si no viniera al caso" (Pautas para conjurados) y de entregarse a la escritura como mero juego lingüístico — sin implicación alguna, en efecto, de saber y de poder- La gratuidad de algunos libros fundacionales de la generación, como el paneriano Así se fundó Carnaby Street, renuentes a asumir "la herencia del modelo de poder establecido" (Lanz, 2011: 154), podría leerse desde esta óptica como un lábil modo de compromiso; por más que, con palabras de Panero referidas a esta época, "la poesía y la política no tenían nada que ver" (en Méndez Rubio, 2004: 218).

\subsection{El irracionalismo}

Si la tendencia al irracionalismo fue uno de los componentes más estables del modelo estético novísimo, ya José María Castellet advertía en el prólogo de su antología sobre los dos modos de manifestarse el cogito interruptus en los poetas seleccionados: mientras en los más jóvenes lo hacía como una consecuencia de la "formación táctil de la personalidad" — dicho en el código de McLuhan-, proveniente de una educación dominada por los media, obedecía en los mayores a un intento de ruptura 
con la lógica lingüística de un statu quo represivo (2001: 34). No hay que olvidar que en la consolidación de este rasgo de la novísima poesía fue también determinante -y ello valía para todos- el apercibimiento de los límites de la razón y su lenguaje para vertebrar una interpretación de la experiencia. Resultaba así que la disgregación lógica del poema era congruente con una percepción discontinua del mundo, y la acumulación no jerarquizada de imágenes y de datos inconexos venía a trasladar una conciencia fragmentada y caótica. Ahora bien, con este aspecto convergía en algunos el deseo de subvertir un instrumento expresivo que revelaba su permeabilidad a la ideología dominante y su docilidad como canal de conducción de los discursos de poder.

No le faltaba razón a Castellet cuando apreciaba esta voluntad en la tentativa de Martínez Sarrión de revalorizar la revolución "alógica" de los surrealistas (2001: 34), quienes, preconizando el automatismo psíquico puro, se habían propuesto atentar contra la codificación moral opresiva de la sociedad burguesa. De hecho, si el surrealismo servía a Sarrión para enunciar el caos de una realidad percibida en su fragmentación, no era menos importante, según el propio poeta llegó a declarar, la fascinación que sobre él ejercía la escuela bretoniana por lo que esta tenía de "rebeldía total, de exaltación del azar, de la libertad sin frenos, del 'amour fou", (en Campbell, 1994: 162). Ahora bien, es seguramente la narratividad sincopada de Vázquez Montalbán la que de modo más consciente elige el cultivo del irracionalismo como forma de dinamitar discursivamente una concepción de poder, que no es otra que la racionalización tecnocrática del último franquismo. A este respecto, no puede resultar más elocuente la declaración de su "Poética" para Nueve novísimos: "Ahora escribo como si fuera idiota, única actitud lúcida que puede consentirse un intelectual sometido a una organización de la cultura precariamente neocapitalista" (en Castellet, 2001: 57). Véase el irónico planteamiento que, en sentido complementario, encierra el generoso rótulo de una composición denunciadora de la manipulación ideológica del lenguaje publicitario seleccionada por Castellet y procedente, no por azar, del montalbaniano Manifiesto subnormal (1970):

POEMA PUBLICITARIO PRESENTADO A LA CONSIDERACIÓN DE UNILEVER. SOBRE EL MÉRITO DE LA MAGIA DE LAS EXTRAÑAS ASOCIACIONES, SE 
UNE LA MAGIA DEL ACTO Y DEL COLOR DANDO UN SENTIDO AL PUÑADO DE IMÁGENES ROTAS BAJO EL SOL. PORQUE LO IMPORTANTE NO ES LA LÓGICA DEL CONTENIDO, SINO LA NUEVA LÓGICA QUE SE ESTABLECE ENTRE EL CONTENIDO Y SU ÚNICA VERIFICACIÓN: EL CONSENSUS DEL MERCADO. TRAS UNA LARGA ETAPA EXPERIMENTAL, ESTOS POEMAS CONSIGUIERON DESPERTAR EL DESEO DE LA LIMPIEZA EN CUATRO DE CADA CINCO MUJERES SOMETIDAS A LA REPETICIÓN MÉTRICA. INCLUSO CONSIGUIERON DESPERTAR ALGUNAS VOCACIONES VESTALES (en Castellet, 2001: 76).

La fórmula estética de Vázquez Montalbán incluía, así pues, la ambición de combatir la colonización ideológica de un poder que se acomodaba en los meandros del lenguaje, y ello pasaba por legitimar el experimentalismo como condición de viabilidad para una verdadera política de vanguardia (Vázquez Montalbán, 1968: 114). No es azaroso que los poetas de Claraboya, que habían condenado el alogicismo novísimo por cuanto no apreciaban en él sino una obediencia al "dictamen desarticulado del subconsciente", que rehuía al cabo la expresión de la realidad, aplaudan en cambio el "narrativismo dinámico" del autor barcelonés, por cuanto sí entroncaba con la "poesía dialéctica" por ellos preconizada: aquella que, concebida como un medio de captación de la realidad contemporánea, demandaba la habilitación de un discurso dislocado y fragmentario susceptible de penetrar su condición convulsa y "rota", y de propiciar el contacto efectivo con la estructura política del país que no habían logrado las "idealistas" fórmulas sociales (Delgado et al., 1971: 20-33). Precisamente, también en la disposición estética de Vázquez Montalbán había una manifiesta voluntad de superar una retórica social considerada no solo formal sino políticamente inoperante. Aunque no se trataba únicamente de la confianza en el fragmentarismo narrativo y la disgregación semántica como dispositivos más eficaces para la captación del mundo; además, la conciencia del discreto potencial de la poesía contra el arsenal propagandístico del sistema permitía romper con el coercitivo precepto de la comunicación, y otorgaba una holgada libertad de ejecución que contaba con el hecho experimental como medio de subversión del 
lenguaje codificado.

\subsection{La realidad}

La "desrealización” de que hablaba Ángel González, entendiendo por tal la elusión de la realidad inmediata como referente del texto y su sustitución por un prestigioso universo simbólico-mítico fue, en efecto, una de las más reconocibles marcas de época. Pero no es menos cierto que, con frecuencia no desdeñable, el empleo de fórmulas elípticas como modo habitual de proceder del patrón estético novísimo no dejó ver una comparecencia de la realidad y de la Historia que incluso en la antología Nueve novísimos se hallaban más presentes de lo que en sus primeras lecturas se apreció. De hecho, o muy especialmente, la poesía de ese novísimo “de refilón” (Gracia, 1990: XIX) que fue Vázquez Montalbán, pero también, aunque en distinta medida, de Martínez Sarrión, no pueden interpretarse sino como un afilado asedio crítico a la realidad socio-política que, si no renuncia a la problematización de los significantes, tampoco lo hace a encauzarse mediante la ironización de los significados. Sin que ello sea incompatible con las reservas que ambos poetas expresaron frente a un periclitado realismo social en el que paradójicamente apreciaban resabios de idealismo, no sin haberlo practicado alguna vez; y es que, como ya advertía Castellet (2001: 27), la ruptura se producía en los mayores a partir de los supuestos precedentes y — cabría agregar - no se consumaba con la radicalidad que lo hacía entre la coqueluche.

La consideración castelletiana que acabamos de evocar resulta incontestablemente verificada por la incorporación de Vázquez Montalbán a la segunda edición de la antología Poesía social (1969) preparada por Leopoldo de Luis: una tribuna que el autor no tiene empacho en emplear en un riguroso ajuste de cuentas con la poética mostrada. "La expresión poesía social — sentenciaba allí - es una convención cultural falsa", ya que su repercusión en la conformación de la conciencia pública deviene insignificante en una situación de cultura de masas dirigida desde la médula del sistema. Esta lucidez conduce al poeta a abandonar cualquier tentación redentorista y libera la creación del "romanticismo formal" que había atenazado a aquel poeta del pueblo ilusionado con redimirlo (en Luis, 1969: 435-437). Ahora bien, la vigilancia escéptica no impide a quien un día se entregó a la explícita protesta — "En mis primeros versos 
pedía libertad, pan, justicia, enseñanza gratuita y amor libre" (en Castellet, 2001: 57) — seguir considerando la palabra como "un instrumento de vinculación moral", e incluso admitir que, si no parece el medio más eficaz para transformar la realidad, "también resulta desaforado descartarla del todo". Por ello el autor, no asintiendo dogmáticamente a la concepción del poema como mero objeto verbal, rompe una lanza por aquellos que exhiben su conexión directa con la realidad (en Campbell, 1994: 144). Y su ejercicio literario constituye de hecho un paradigma de vinculación crítica con el entorno, como así lo expresara muy tempranamente Félix Grande - "no hay ni un solo texto de Vázquez Montalbán que no esté vinculado a la realidad — precisamente política" (1970: 101)—y ha venido a certificar cumplidamente el discurso crítico (por lo que no abundaremos en ello aquí).

No hallamos, en cambio, igual determinación a la hora de atestiguar los nexos con la Historia que tienden los versos de Martínez Sarrión, sin duda porque la dicción deliberadamente elíptica y la creciente desvertebración verbal a que propende este autor en su etapa novísima dificultan sensiblemente su discernimiento. Sin embargo, el poeta albaceteño encarna la puesta en juego de una experimentación formal tan alejada del embellecimiento preciosista como atenta al referente extrapoético. El sesgo vanguardista de su lenguaje se halla presidido por una inalterable voluntad ética, que se acompaña de la constatación de la obsolescencia de las fórmulas socialrealistas — también por él cultivadas en su prehistoria lírica - en su afán de incidir en la realidad. No obstante, su respeto por la función del intelectual en la sociedad, así como por quienes concibieron la poesía como un instrumento de agitación política, mitigaron el rigor de sus juicios sobre una literatura social que, si cayó en la trampa de la abstracción y se resintió, en casos, de falta de calidad, "aportó un enorme caudal de experiencia dentro del cual se cuentan los callejones sin salida que había que superar" (en Castellet, 2001: 87-90).

Desde estos presupuestos, se comprende que el rupturismo de Martínez Sarrión no pase por desenraizar su obra lírica de la circunstancia histórica, antes al contrario: el poeta "habla desde un tiempo y un espacio concretos con los que está en contacto cada palabra escrita" (Provencio, 1988: 25), aunque no se atenga esta a la palmariedad enunciativa de la vieja poesía de protesta. Aun así, los puentes entre la realidad y el texto se tienden con toda evidencia en el conjunto de estampas infantiles que 
componen Teatro de operaciones, libro inaugural del poeta que reúne los ingredientes de una educación sentimental y que registra, como veíamos en "el cine de los sábados", la vida sórdida e inhóspita de la alta posguerra en que aquella tiene lugar. $\mathrm{Y}$ es que la íntima necesidad de proceder a la "exorcización" de una infancia feliz solo en apariencia (Martínez Sarrión, en Campbell, 1994: 163) solicita el ejercicio testimonial y una autoindagación en clave histórica, aunque esta se halle embozada tras un descoyuntamiento verbal confiado a dispositivos de raíz vanguardista. Sin embargo, la incapacidad del hablante para la evasión de un entorno con el que es preciso ajustar cuentas se declara sin ambages en el último poema del libro, una confrontación dialéctica entre escapismo y testimonio, esteticismo y compromiso, que reclama el derecho a acogerse a los segundos términos del binomio una vez constatado el imposible refugio en la belleza:

\author{
un día \\ pintaremos ya calmados \\ quién sabe qué paisaje \\ qué corza \\ qué pez en una pieza de cerámica \\ trazos \\ que volverán a ser humanos tiempo \\ de la alegría \\ pero dejadme ahora \\ dejadme hablar a tiros
}

de estos paseos de estas tardes de estas

cuatro paredes tan inhabitables

de la vieja maldita fruta amarga

que se nos ha podrido muy adentro

hasta contaminar el corazón (Martínez Sarrión, 1981: 84).

La naturaleza extraordinariamente críptica de Pautas para conjurados, segunda entrega de Martínez Sarrión en la que se adivina un claro propósito de obturación de los significados (cuyas pautas secretas comparten los conjurados del título como herramienta principal de subversión), no renuncia a las continuas alusiones a la realidad inmediata, pero vuelve más sinuosa la entonación crítica que subyace a los textos. 
El poeta ha atribuido el tono "formalmente más abrupto" de este libro a la atmósfera "enrarecida" y "neurotizante" del momento biográfico e histórico en que se compuso (en Campbell, 1994: 160): los últimos coletazos del mayo francés, con el adelgazamiento consiguiente de las ilusiones revolucionarias, que invitan a la expresión del malestar por la vía de una doble insurrección, relativa a los significados tanto como a los significantes. Repárese, a este respecto, en la irónica consideración metapoética que abre "Ritual de los apocalípticos", y que sugiere explícitamente la coexistencia de experimentación vanguardista y contestación política: "Si de lo que en rigor se trata es de sorprender a las muchedumbres ejecutando cabriolas verbales en fechas muy señaladas (en rojo) he aquí el resultado que contabilizo" (1981: 94).

Así las cosas, la distancia frente al realismo social se establece más que nunca en la deliberada transgresión del lenguaje pautado, pero también en un creciente desencanto respecto del hecho de escribir congruente con el desmantelamiento de las esperanzas colectivas que habían nutrido la utopía sesentayochista. Resulta, a este propósito, particularmente elocuente la composición "De la inutilidad de conspirar en librerías de viejo", perteneciente al mismo conjunto en que comienza a apuntar el desbaratamiento de aquel sueño generacional con el que se intentara "afrontar el desastre" de la realidad, según precisamente declara el arranque del poema. Ese "desastre" histórico se representa en el texto mediante un cúmulo de referencias a la guerra civil (la batalla de Guadarrama, el presidente Juan Negrín, el campo de Argelès-sur-Mer), suceso no padecido directamente por el hablante, pero cuyo recuerdo traumático aún flota en la conciencia colectiva durante sus años de formación; mientras que las veleidades conspiratorias anunciadas en el título, que condensan la propuesta de acción del espíritu del 68, toman cuerpo en "las mostrencas teorías de Koprotkin" atrapadas en los anaqueles de libros prohibidos. Ahora bien, el voluntarismo ético que preside la conducta del sujeto acaba por estrellarse contra la lúcida conciencia de la futilidad de la escritura, según se infiere de unos versos que expresan el contraste entre la efectiva "historia de los hombres" y las elucubraciones literarias —o, con palabras de Prieto de Paula, entre "la revolución y las meras maquinaciones intelectuales sometidas a la congelación de la letra muerta" (1996: 71)—:

\section{$Y$ de este modo}


el invisible mago de los libros

el hombre de las trenzas conservadas en talco

recibe cada tarde las visitas sonámbulas de los viejos repúblicos

de las muchachas de las sindicales

mansamente vestidas ahora de marrón Y se intenta

remover la vergüenza Se convocan en sueños

las cohortes brutales de los senegaleses

en las pocilgas de Argelès

el culo al viento los torrentes

de lágrimas inútiles

mientras la historia de los hombres sigue

ante sus ojos congelados (Martínez Sarrión, 1981: 99-100).

Al convencimiento último "de la inutilidad de conspirar en librerías de viejo", esto es, de la condición fantasmal de la escritura y la inanidad del ejercicio intelectual como medio de intervención en una Historia a la que, al cabo, solo accede el poeta a través de los libros no es seguramente ajeno el discurso roto y dislocado en que se resuelve el poema, y que funciona a la postre como síntoma de un vivo sentimiento de impotencia. Sin duda, la misma lúcida impotencia que disuade a la mayoría de los poetas novísimos del establecimiento de vínculos entre lenguaje y realidad.

Claro que se han registrado, a cambio, tentativas de contravenir lo estatuido mediante la que ha sido llamada "realidad del lenguaje". Pero, aun por esta vía, la integración de lo político en el poema se dio más raramente de lo que algunas lecturas (y, sobre todo, autolecturas) a posteriori han querido proponer. Al cabo, la poesía había dejado atrás el "contrato social" al que — según recordara Blas de Otero - obligaba la noción de engagement, y el derecho de autonomía estética era reclamado por encima de todos. Ello no debe inducirnos a eludir el alcance subversivo que sin duda desvelan algunos rasgos centrales del modelo estético novísimo - el culturalismo, el camp, la metapoesía, el irracionalismo- y que determinadas inercias críticas todavía demasiado arraigadas han tendido a ver como mecanismos evasivos o autorreferentes, al no contemplar el desplazamiento de la conciencia política hacia una problematización del trabajo textual. Sin embargo, y con todo, si hemos de arriesgar una generalización, nos inclinamos a pensar, con Guillermo Carnero, que la 
poesía novísima fue antes que nada esa proclamación de libertad respecto de los condicionamientos históricos, y que, si algo la singularizó en este punto, fue su renuencia a "prestar al franquismo el acatamiento que en última instancia era tenerlo como objeto de atención" (en Méndez Rubio, 2004: 125).

\section{REFERENCIAS BIBLIOGRÁFICAS}

BATLlÓ, J. (ed.) (1974). Poetas españoles poscontemporáneos. Barcelona: El Bardo.

BOUSOÑO, C. (1983). "La poesía de Guillermo Carnero". En Ensayo de una teoría de la visión, G. Carnero, 9-68. Madrid: Hiperión.

CAMPBELL, F. (1994). Infame turba. Barcelona: Lumen.

CARNERO, G. (1983). "La corte de los poetas. Los últimos veinte años de poesía española en castellano". Revista de Occidente 23, 43-59.

(1990). "Culturalismo y poesía novísima. Un poema de Pedro Gimferrer: 'Cascabeles' de Arde el mar". En Novísimos, postnovísimos, clásicos. La poesía de los ochenta en España, B. Ciplijauskaité (ed.), 11-23. Madrid: Orígenes.

CASTELLET, J. M. ${ }^{\mathrm{a}}$ (ed.) (2001). Nueve novísimos poetas españoles. Barcelona: Península.

CHÁVARRI, J. (1976). El desencanto. Madrid: Elías Querejeta Ediciones. CUENCA, L. A. de (1979-1980). "La generación del lenguaje". Poesía 5-6, 245-251.

DADSON, T. (2000). "La reapropiación del lenguaje poético del franquismo: el caso de Dibujo de la muerte de Guillermo Carnero". En Voces subversivas. Poesía bajo el régimen (1939-1975), T. Dadson y D. W. Flitter (eds.), 119-142. Birmingham: University of Birmingham.

DELGADO, A. et al. (1971). Equipo “Claraboya”. Teoría y poemas. Barcelona: El Bardo.

GARCÍA DE LA CONCHA, V. (1972). “Primera etapa de un 'novísimo': Pedro Gimferrer: Arde el mar". Papeles de Son Armadans CXC, 4561.

(1986). "La renovación estética de los años sesenta". Los Cuadernos 
del Norte, monografías 3, 10-22.

GIL DE BIEDMA, J. (1994). El pie de la letra. Barcelona: Crítica.

GIMFERRER, P. (1996). Itinerario de un escritor. Barcelona: Anagrama.

GONZÁLEZ, Á.(1980). “Poesía española contemporánea”. Los Cuadernos del Norte, monografías 3, 4-7.

GRACIA, J. (1990). “Gimferrer en los Nueve novísimos o la coherencia de una poética". Anthropos 110-111, XVII-XX.

GRANDE, F. (1970). Apuntes sobre poesía española de posguerra. Madrid: Taurus.

LANZ, J. J. (ed.) (1997). Antología de la poesía española 1960-1975. Madrid: Espasa Calpe.

(2011). Nuevos y novísimos poetas en la estela del 68. Sevilla: Renacimiento.

LUIS, L. de (ed.) (1969). Poesía social. Antología (1939-1968). Madrid: Alfaguara.

MARTÍN PARDO, E. (ed.) (1990). Nueva poesía española (1970). Antología consolidada (1990). Madrid: Hiperión.

MARTÍNEZ RUIZ, F. (ed.) (1971). La nueva poesía española. Antología crítica. Segunda generación de posguerra (1955-1970). Madrid: Biblioteca Nueva.

MARTÍNEZ SARRIÓN, A. (1981). El centro inaccesible (Poesía 19671980). Madrid: Hiperión.

MÉNDEZ RUBIO, A. (2002). “Otra poesía es posible. La cuestión del sujeto y la crítica social en la poesía reciente”. Ínsula 671-672, 4244.

(2004). Poesía '68. Para una historia imposible: escritura y sociedad 1968-1978. Madrid: Biblioteca Nueva.

(2007). "El canon del compromiso". Prosopopeya 5, 209-230.

PANERO, L. M.. (2001). Poesía completa. 1970-2000. Madrid: Visor.

PRAT, I. (1983). Estudios sobre poesía contemporánea. Madrid: Taurus.

PRIETO DE PAULA, Á. L. (1996). Musa del 68. Madrid: Hiperión.

PROVENCIO, P. (1988). Poéticas españolas contemporáneas. La generación del 70. Madrid: Hiperión.

RODRÍGUEZ, J. C. (1999). Dichos y escritos (Sobre "La otra sentimentalidad" y otros textos fechados de poética). Madrid: Hiperión.

(2002). "El yo poético y las perplejidades del compromiso". Ínsula 
671-672, 53-56.

SILES, J. (1989). “Los novísimos: la tradición como ruptura, la ruptura como tradición". Ínsula 595, 9-11.

TALENS, J. (1981). “(Desde) la poesía de Antonio Martínez Sarrión”. En El centro inaccesible (Poesía 1967-1980), A. Martínez Sarrión, 7-37. Madrid: Hiperión.

VÁZQUEZ MONTALBÁN, M. (1968). "Experimentalismo, vanguardia y neocapitalismo". En Reflexiones ante el neocapitalismo, VV. AA., 105-116. Barcelona: Ediciones de Cultura Popular.

Recibido el 12 de febrero de 2017.

Aceptado el 14 de marzo de 2017. 
